Article

\title{
Crystal Structures of 1-Hydroxyimidazole and Its Salts
}

\section{Gerhard Laus $^{1, *}$ and Volker Kahlenberg ${ }^{2}$}

1 Faculty of Chemistry and Pharmacy, University of Innsbruck, 6020 Innsbruck, Austria

2 Institute of Mineralogy and Petrography, University of Innsbruck, 6020 Innsbruck, Austria;

E-Mail: volker.kahlenberg@uibk.ac.at

* Author to whom correspondence should be addressed; E-Mail: gerhard.laus@uibk.ac.at; Tel.: +43-512-507-57080; Fax: +43-512-507-57099.

Received: 19 September 2012; in revised form: 28 September 2012 / Accepted: 9 October 2012 / Published: 31 October 2012

\begin{abstract}
The crystal structures of 1-hydroxyimidazole and four protic salts (chloride, bromide, sulfate, nitrate) thereof were determined. The molecular geometries (bond lengths and angles) of the free base and the salts were compared. Hydrogen bonding patterns were studied, and $\mathrm{OH} \cdots \mathrm{N}, \mathrm{OH} \cdots \mathrm{Cl}, \mathrm{OH} \cdots \mathrm{Br}, \mathrm{OH} \cdots \mathrm{O}, \mathrm{NH} \cdots \mathrm{Cl}, \mathrm{NH} \cdots \mathrm{Br}$, and $\mathrm{NH} \cdots \mathrm{O}$ interactions were identified. Hirshfeld surface analysis gave quantitative insight into these interactions.
\end{abstract}

Keywords: hydrogen bond; hydroxyimidazole; imidazole; Hirshfeld surface analysis

\section{Introduction}

Synthetic routes to 1-hydroxyimidazoles include cyclization of linear precursor molecules, condensation of small fragments, oxidation of imidazole, and partial reduction of 1,3-dihydroxy-imidazolium salts. Early reports on the preparation of 2,4,5-trisubstituted 1-hydroxyimidazoles [1-3] showed considerable uncertainty about the constitution of the product (an epoxide structure was assumed). Then, an unambiguous synthesis of 4,5-disubstituted 1-hydroxyimidazoles has been described [4]. Several attempts have been made to prepare the interesting and simple title compound, 1-hydroxyimidazole. The first attempts ended up with benzyloxy or imidazolinone derivatives, stopping just short of the desired target $[5,6]$. Considerable time has now passed by since the first practical synthesis of 1-hydroxyimidazole has been reported, involving selective hydrogenation of 1,3-dihydroxyimidazolium chloride [7]. Other syntheses of this 
compound have been published in the meantime. Oxidation of imidazole gave only very low yields (using peroxyphthalic acid [8] or 3-chloroperoxybenzoic acid [9,10]). A better strategy involved mono-benzylation of 1-hydroxyimidazole-3-oxide, followed by deoxygenation using phosphorus trichloride and hydrogenolytic debenzylation [10]. Thus, several synthetic methods are now available, and the subsequent preparation of derivatives has been disclosed [10-16]. The effects of hetero-atom substituents from the second and third row of the periodic table at the nitrogen atom of imidazole have been studied by theoretical methods [17]. However, no experimental details of the molecular geometry of 1-hydroxyimidazole or its salts have yet been reported.

\section{Results and Discussion}

Here we present the crystal structures of the title compound and four of its salts. The hydrochloride $[8,10,14]$ and hydrobromide [9] of 1-hydroxyimidazole are known, but no crystal structure has been reported. We determined the structures of these known compounds and the new salts, sulfate and nitrate. The salts were obtained either by metathesis or by proton transfer. Crystal data and refinement details are summarized in Table 1. Hydrogen bond parameters are collected in Table 2.

Table 1. Crystal data and structure refinement details.

\begin{tabular}{|c|c|c|c|c|c|}
\hline Compound & 1 & 2 & 3 & 4 & 5 \\
\hline CCDC no. & 899,476 & 899,477 & 899,478 & 899,479 & 899,480 \\
\hline Chemical formula & $\mathrm{C}_{3} \mathrm{H}_{4} \mathrm{~N}_{2} \mathrm{O}$ & $\mathrm{C}_{3} \mathrm{H}_{5} \mathrm{~N}_{2} \mathrm{O} \cdot \mathrm{Cl}$ & $\mathrm{C}_{3} \mathrm{H}_{5} \mathrm{~N}_{2} \mathrm{O} \cdot \mathrm{Br}$ & $2\left(\mathrm{C}_{3} \mathrm{H}_{5} \mathrm{~N}_{2} \mathrm{O}\right) \cdot \mathrm{O}_{4} \mathrm{~S}$ & $\mathrm{C}_{3} \mathrm{H}_{5} \mathrm{~N}_{2} \mathrm{O} \cdot \mathrm{NO}_{3}$ \\
\hline$M_{\mathrm{r}}$ & 84.08 & 120.54 & 164.99 & 266.24 & 147.10 \\
\hline Crystal size $/ \mathrm{mm}^{3}$ & $\begin{array}{c}0.40 \times 0.20 \times \\
0.16\end{array}$ & $\begin{array}{c}0.32 \times 0.30 \times \\
0.16\end{array}$ & $\begin{array}{c}0.26 \times 0.20 \times \\
0.20\end{array}$ & $\begin{array}{c}0.48 \times 0.28 \times \\
0.28\end{array}$ & $\begin{array}{c}0.23 \times 0.11 \times \\
0.11\end{array}$ \\
\hline Crystal system & Orthorhombic & Monoclinic & Monoclinic & Triclinic & Monoclinic \\
\hline Space group & $P 2_{1} 2_{1} 2_{1}$ & $P 2_{1} / n$ & $P 2_{1} / n$ & $P \overline{1}$ & $C c$ \\
\hline$a / \AA$ & $5.1024(3)$ & $4.2693(2)$ & $4.4182(2)$ & $6.5611(10)$ & $3.6216(6)$ \\
\hline$b / \AA$ & $8.2922(5)$ & $10.7541(4)$ & $11.0416(6)$ & $7.7322(11)$ & $17.385(3)$ \\
\hline$c / \AA \AA$ & $9.3064(6)$ & $10.9756(4)$ & $11.2015(6)$ & $12.1134(14)$ & $9.0259(13)$ \\
\hline$\alpha /^{\circ}$ & 90 & 90 & 90 & $97.820(11)$ & 90 \\
\hline$\beta /{ }^{\circ}$ & 90 & $93.535(3)$ & $94.081(4)$ & $91.912(11)$ & $90.499(13)$ \\
\hline$\gamma /{ }^{\circ}$ & 90 & 90 & 90 & $113.295(14)$ & 90 \\
\hline$V / \AA^{3}$ & $393.75(4)$ & $502.96(4)$ & $545.07(5)$ & $556.62(13)$ & $568.26(16)$ \\
\hline$Z$ & 4 & 4 & 4 & 2 & 4 \\
\hline$D_{x} / \mathrm{g} \cdot \mathrm{cm}^{-3}$ & 1.42 & 1.59 & 2.01 & 1.59 & 1.72 \\
\hline$\mu / \mathrm{mm}^{-1}$ & 0.94 & 0.63 & 7.42 & 0.32 & 1.41 \\
\hline$F(000) / \mathrm{e}$ & 176 & 248 & 320 & 276 & 304 \\
\hline Radiation & $\mathrm{Cu} K \alpha$ & Mo $K \alpha$ & Mo $K \alpha$ & Mo $K \alpha$ & $\mathrm{Cu} K \alpha$ \\
\hline$\theta_{\max } / \circ$ & 67.4 & 25.4 & 25.3 & 25.4 & 67.6 \\
\hline & $-6 \leq h \leq 6$ & $-5 \leq h \leq 3$ & $-5 \leq h \leq 5$ & $-6 \leq h \leq 7$ & $-4 \leq h \leq 4$ \\
\hline$h, k, l$ range & $-9 \leq k \leq 8$ & $-12 \leq k \leq 12$ & $-13 \leq k \leq 10$ & $-8 \leq k \leq 9$ & $-17 \leq k \leq 20$ \\
\hline & $-11 \leq l \leq 11$ & $-11 \leq l \leq 13$ & $-13 \leq k \leq 12$ & $-12 \leq l \leq 14$ & $-10 \leq k \leq 10$ \\
\hline Measured reflections & 2571 & 2909 & 3152 & 3377 & 1946 \\
\hline $\begin{array}{l}\text { Independent } \\
\text { reflections }\left(R_{\text {int }}\right)\end{array}$ & $690(0.024)$ & $915(0.022)$ & $1001(0.030)$ & $2015(0.025)$ & $808(0.031)$ \\
\hline
\end{tabular}


Table 1. Cont.

\begin{tabular}{cccccc}
\hline Observed reflections & 663 & 852 & 917 & 1618 & 781 \\
{$[I \geq 2 \sigma(I)]$} & & & & & \\
Restraints/parameters & $1 / 59$ & $2 / 72$ & $0 / 73$ & $25 / 194$ & $2 / 99$ \\
$R_{1} / w R_{2}[I \geq 2 \sigma(I)]$ & $0.030 / 0.082$ & $0.023 / 0.061$ & $0.019 / 0.045$ & $0.039 / 0.086$ & $0.031 / 0.074$ \\
$R_{1} / w R_{2}$ (all data) & $0.032 / 0.083$ & $0.025 / 0.063$ & $0.023 / 0.047$ & $0.054 / 0.097$ & $0.032 / 0.075$ \\
Goodness of fit & 1.06 & 1.12 & 0.91 & 1.04 & 1.10 \\
$\Delta \rho_{\max / \min } / \mathrm{e}^{-3}$ & $0.14 /-0.14$ & $0.17 /-0.34$ & $0.31 /-0.26$ & $0.21 /-0.36$ & $0.16 /-0.27$ \\
\hline
\end{tabular}

Table 2. Hydrogen bond parameters $\left(\AA,{ }^{\circ}\right)$.

\begin{tabular}{cccccc}
\hline & Interaction & H $\cdots \mathbf{A}$ & $\mathbf{D} \cdots \mathbf{A}$ & $\mathbf{D}-\mathbf{H} \cdots \mathbf{A}$ & Symmetry A \\
\hline \multirow{2}{*}{1} & $\mathrm{O} 1-\mathrm{H} \cdots \mathrm{N} 2$ & $1.66(1)$ & $2.537(2)$ & $173(2)$ & $3 / 2-x,-y,-1 / 2+z$ \\
& $\mathrm{C} 1-\mathrm{H} \cdots \mathrm{O} 1$ & $2.215(1)$ & $3.141(2)$ & $164.5(1)$ & $-1 / 2+x, 1 / 2-y, 1-z$ \\
2 & $\mathrm{O} 1-\mathrm{H} \cdots \mathrm{Cl}$ & $2.06(2)$ & $2.930(1)$ & $174(2)$ & $1 / 2-x, 1 / 2+y, 1 / 2-z$ \\
& $\mathrm{~N} 1-\mathrm{H} \cdots \mathrm{Cl}$ & $2.43(2)$ & $3.136(1)$ & $143(2)$ & $-1+x, y, z$ \\
& $\mathrm{~N} 2-\mathrm{H} \cdots \mathrm{Cl}$ & $2.86(2)$ & $3.357(1)$ & $120(1)$ & $-x,-y,-z$ \\
3 & $\mathrm{O} 1-\mathrm{H} \cdots \mathrm{Br}$ & $2.29(4)$ & $3.090(2)$ & $169(4)$ & $1 / 2-x, 1 / 2+y, 1 / 2-z$ \\
& $\mathrm{~N} 2-\mathrm{H} \cdots \mathrm{Br}$ & $2.66(3)$ & $3.301(2)$ & $143(3)$ & $-1+x, y, z$ \\
& $\mathrm{~N} 2-\mathrm{H} \cdots \mathrm{Br}$ & $2.98(3)$ & $3.470(2)$ & $124(3)$ & $-x,-y,-z$ \\
4 & $\mathrm{O} 1-\mathrm{H} \cdots \mathrm{O} 3 \mathrm{~A}$ & $1.67(2)$ & $2.51(1)$ & $162(2)$ & $-x, 1-y, 1-z$ \\
& $\mathrm{O} 1-\mathrm{H} \cdots \mathrm{O} 3 \mathrm{~B}$ & $1.61(2)$ & $2.46(1)$ & $168(3)$ & $-x, 1-y, 1-z$ \\
& $\mathrm{O} 1 \mathrm{~A}-\mathrm{H} \cdots \mathrm{O} 5 \mathrm{~A}$ & $1.62(3)$ & $2.46(2)$ & $166(3)$ & $x,-1+y, z$ \\
& $\mathrm{O} 1 \mathrm{~A}-\mathrm{H} \cdots \mathrm{O} 5 \mathrm{~B}$ & $1.68(3)$ & $2.54(1)$ & $169(3)$ & $x,-1+y, z$ \\
& $\mathrm{~N} 2-\mathrm{H} \cdots \mathrm{O} 2$ & $1.85(2)$ & $2.704(3)$ & $169(2)$ & $-x, 1-y, 1-z$ \\
& $\mathrm{~N} 2 \mathrm{~A}-\mathrm{H} \cdots \mathrm{O} 2$ & $1.89(2)$ & $2.739(2)$ & $175(2)$ & $1 / 2+x, 3 / 2-y,-1 / 2+z$ \\
5 & $\mathrm{O} 1-\mathrm{H} \cdots \mathrm{O} 2$ & $1.65(4)$ & $2.596(2)$ & $178(4)$ & $1 / 2+x, 3 / 2-y, 1 / 2+z$ \\
\hline & $\mathrm{N} 2-\mathrm{H} \cdots \mathrm{O} 4$ & $1.98(4)$ & $2.803(3)$ & $176(3)$ &
\end{tabular}

When the molecular geometries of the imidazole rings in the free base and the protic salts are compared, two points immediately become apparent. The bond lengths in the heterocyclic system do not change significantly upon protonation, but the angles do (Figure 1). Thus, the angles at the nitrogen atoms $(\mathrm{C} 1-\mathrm{N} 1-\mathrm{C} 3$ and $\mathrm{C} 1-\mathrm{N} 2-\mathrm{C} 2$; for numbering see Figure $2 \mathrm{a})$ are increased in the protonated imidazolium molecules by $1.7^{\circ}$ and $3.4^{\circ}$ (average values), respectively. In contrast, the mean angles $\mathrm{N} 1-\mathrm{C} 1-\mathrm{N} 2$ and $\mathrm{N} 2-\mathrm{C} 2-\mathrm{C} 3$ are decreased by $3.2^{\circ}$ and $2.2^{\circ}$, respectively. This situation was predicted by theoretical calculations [18]. The angle N1-C3-C2, however, does not change significantly. 
Figure 1. Bond lengths and angles in the heterocyclic system of (a) 1-hydroxyimidazole; (b) 1-hydroxyimidazole hydrochloride; (c) 1-hydroxyimidazole hydrobromide; (d) and (e) the two independent cations of bis(1-hydroxyimidazolium) sulfate, and (f) 1-hydroxyimidazolium nitrate.

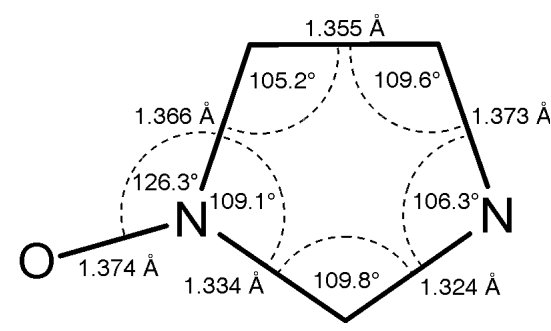

(a)

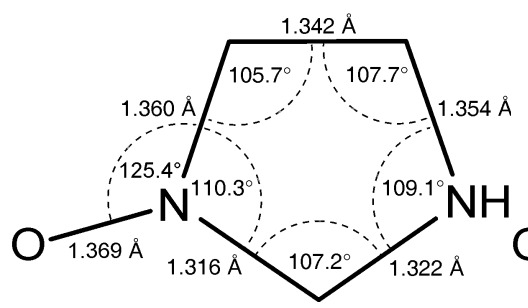

(d)

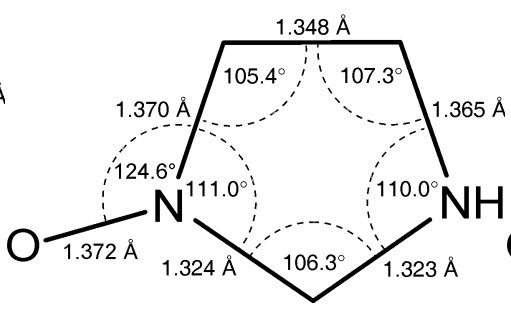

(b)

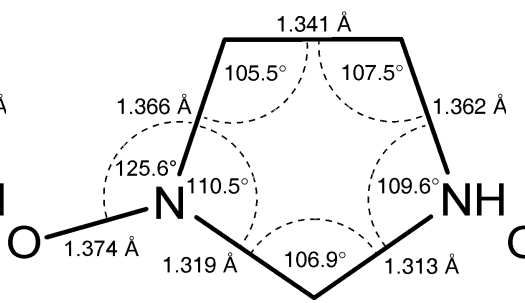

(e)

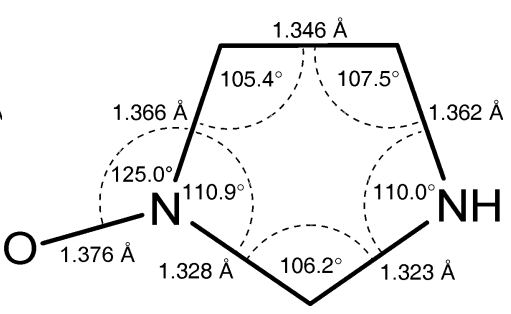

(c)

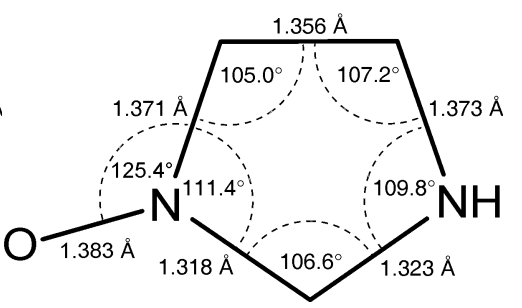

(f)

Figure 2. (a) ORTEP plot with numbering scheme and (b) hydrogen bonding in the crystal structure of 1-hydroxyimidazole (1).

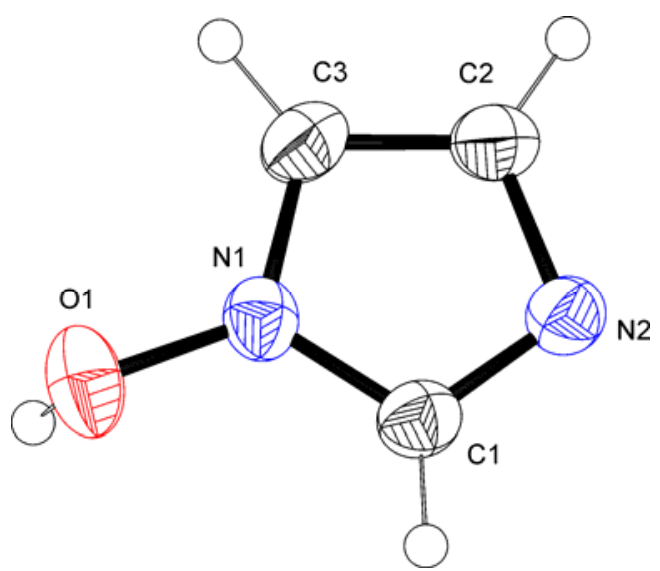

(a)

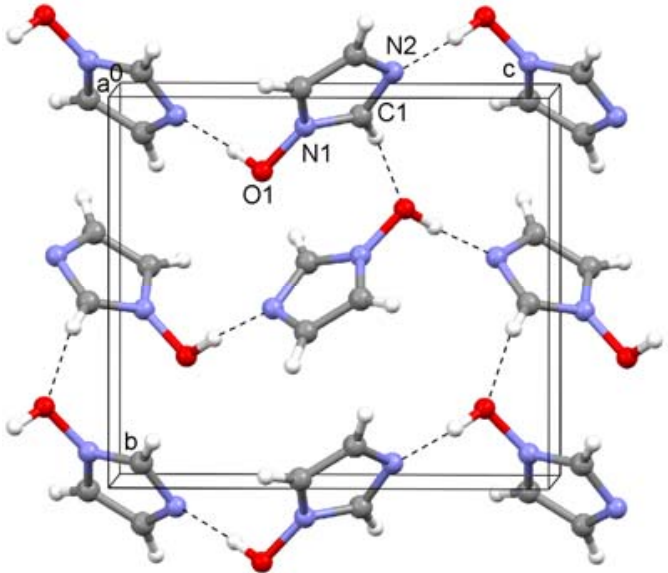

(b)

\subsection{1-Hydroxyimidazole (1)}

The molecular structure is shown in Figure 2a. The heterocyclic molecules are arranged in chains by $\mathrm{O}-\mathrm{H} \cdots \mathrm{N}$ hydrogen bonds in the $\left[\begin{array}{lll}0 & 0 & 1\end{array}\right]$ direction (Figure 2b). Additional $\mathrm{C} 1-\mathrm{H} \cdots \mathrm{O} 1$ contacts create a three-dimensional network. Due to the lack of heavy atoms a meaningless Flack parameter of 0.43(40) was obtained, and the absolute structure of the chiral crystal was not determined. 


\subsection{1-Hydroxyimidazole Hydrochloride (2)}

The ions in this structure exhibit $\mathrm{O}-\mathrm{H} \cdots \mathrm{Cl}^{-}$and $\mathrm{N}-\mathrm{H} \cdots \mathrm{Cl}^{-}$hydrogen bonds. The zig-zag chains thus formed propagate in the direction of the crystallographic $b$ axis. These chains are connected by additional weak $\mathrm{N}-\mathrm{H} \cdots \mathrm{Cl}^{-}$contacts (Figure 3). In contrast to the structure of the title compound $\mathbf{1}$, there are no significant contacts involving $\mathrm{C} 1-\mathrm{H}$.

Figure 3. Hydrogen bonding in the crystal structures of (a) 1-hydroxyimidazole hydrochloride (2).

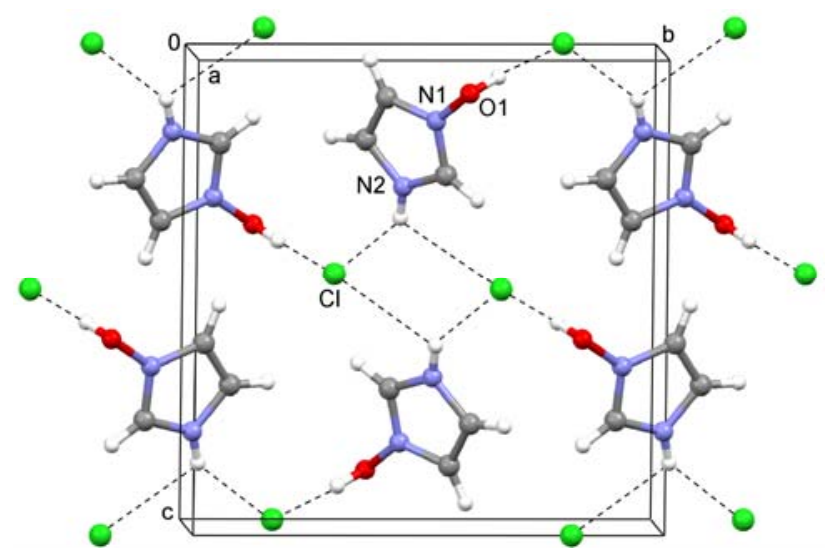

\subsection{1-Hydroxyimidazole Hydrobromide (3)}

As expected, the structures of the hydrobromide and the hydrochloride are isomorphic, and the ions form $\mathrm{O}-\mathrm{H} \cdots \mathrm{Br}^{-}$and $\mathrm{N}-\mathrm{H} \cdots \mathrm{Br}^{-}$hydrogen bonds again in the direction of the crystallographic $b$ axis.

\subsection{Bis(1-hydroxyimidazolium) Sulfate (4)}

Two independent cations are observed in this structure. The sulfate ion is disordered showing split positions for two of its four oxygen atoms. Interionic $\mathrm{O}-\mathrm{H} \cdots \mathrm{O}$ and $\mathrm{N}-\mathrm{H} \cdots \mathrm{O}$ hydrogen bonds are displayed in Figure 4a. In another view, the cyclic arrangement of two cations plus two anions can be seen (Figure 4b).

Figure 4. (a) Hydrogen bonding and (b) cyclic arrangement of the ions in bis(1-hydroxyimidazolium) sulfate (4).

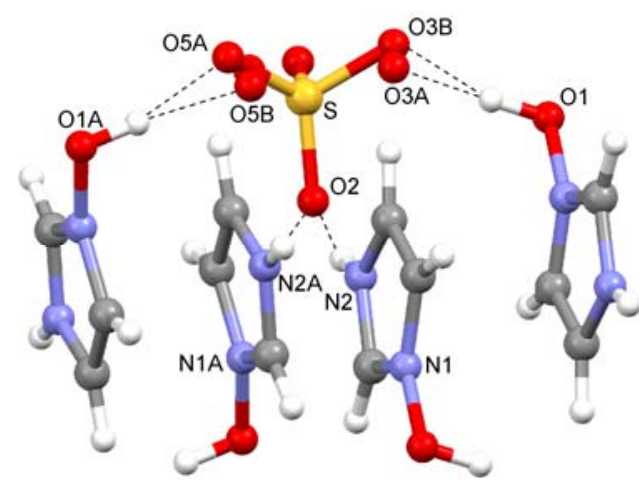

(a)

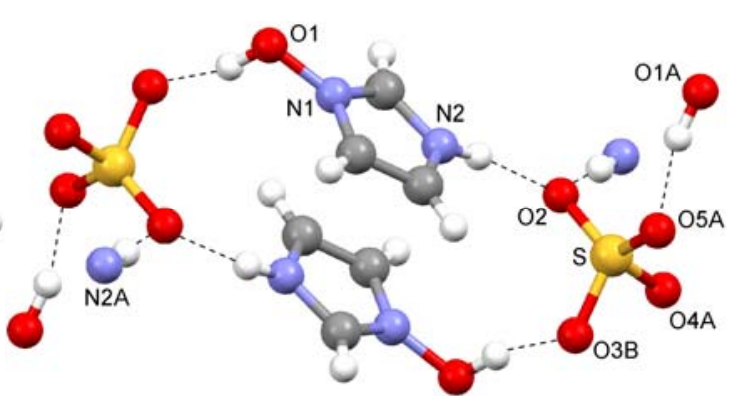

(b) 


\subsection{1-Hydroxyimidazolium Nitrate (5)}

Interionic $\mathrm{O}-\mathrm{H} \cdots \mathrm{O}$ and $\mathrm{N}-\mathrm{H} \cdots \mathrm{O}$ hydrogen bonds are observed in this crystal structure (Figure 5). These interactions form infinite chains which propagate in the direction of the crystallographic $c$ axis.

Figure 5. Hydrogen bonding in the crystal structure of 1-hydroxyimidazolium nitrate (5).

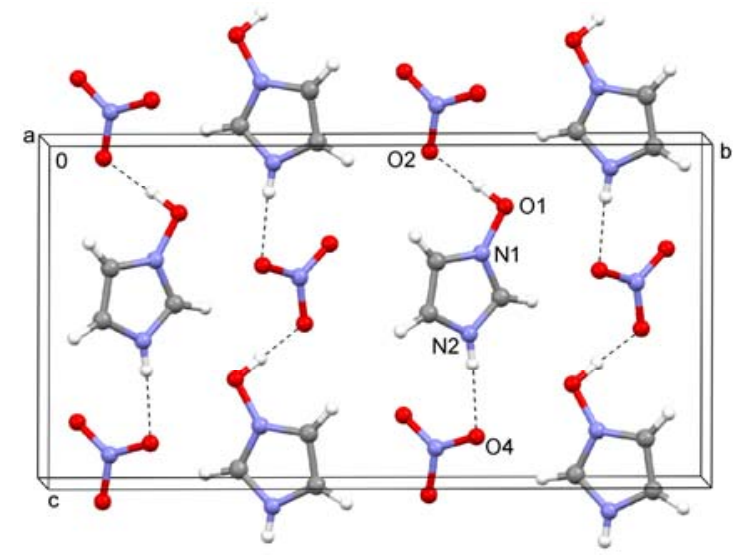

\subsection{Hirshfeld Surface Analysis}

Electrostatic potential mapped on the Hirshfeld surface [19] clearly shows the positions of close intermolecular contacts in 1-hydroxyimidazole (1) (Figure 6a). The $d_{\mathrm{e}} / d_{\mathrm{i}}$ plots are dominated by the hydrogen-bonding fingerprints. Two distinct $\mathrm{O} \cdots \mathrm{H}$ and $\mathrm{N} \cdots \mathrm{H}$ interactions are observed as sharp spikes in Figure 6b,c (reciprocal interactions included). The upper spike corresponds to the hydrogen-bond donor. The fingerprint plots for the cations of the salts are quite different from those observed for the molecular crystal of $\mathbf{1}$. The unidirectional hydrogen-bond donation to the anion is highlighted in these plots, the full fingerprint appears as a gray shadow (Figure 7). In the sulfate the hydrogen-bond spike is broadened because of the presence of several $\mathrm{H} \cdots \mathrm{O}$ interactions. The quantitative results of the Hirshfeld surface analysis are presented in Table 3.

Figure 6. (a) Normalized Hirshfeld surface of 1-hydroxyimidazole and associated fingerprint plots highlighting specific interactions; (b) $\mathrm{O} \cdots \mathrm{H}$ and (c) $\mathrm{N} \cdots \mathrm{H}$.

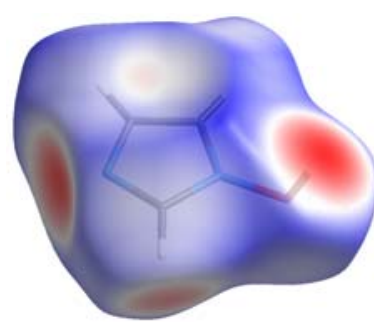

(a)

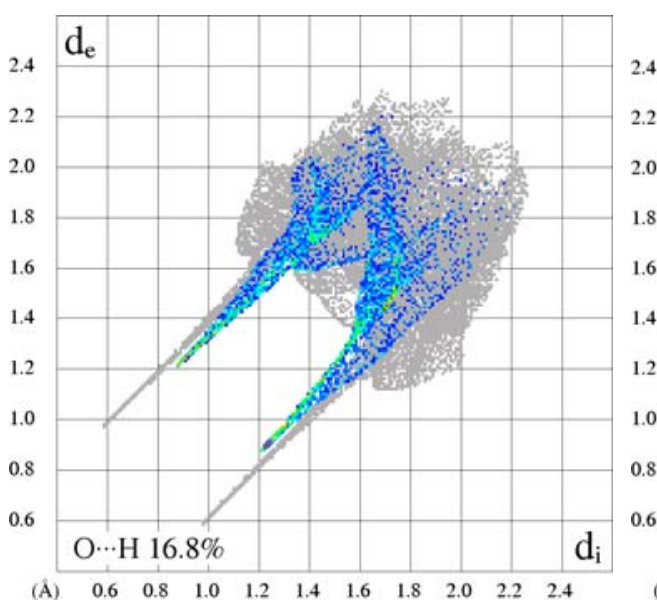

(b)

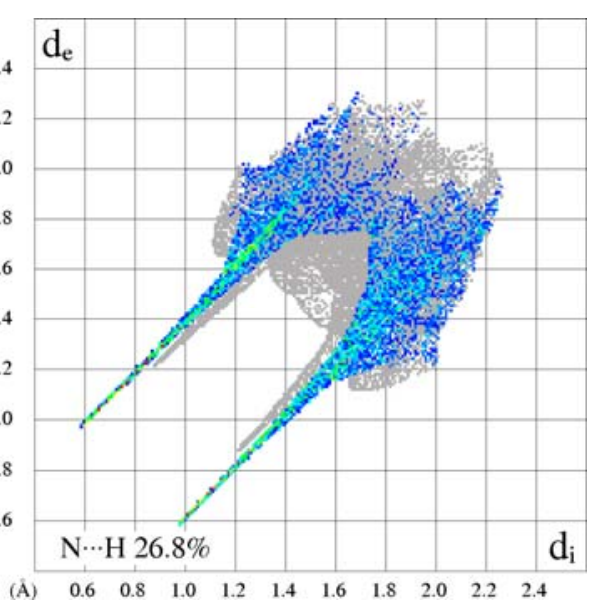

(c) 
Figure 7. Two-Dimensional fingerprint plots of (a) 1-hydroxyimidazole hydrochloride; (b) bis(1-hydroxyimidazolium) sulfate; and (c) 1-hydroxyimidazolium nitrate.

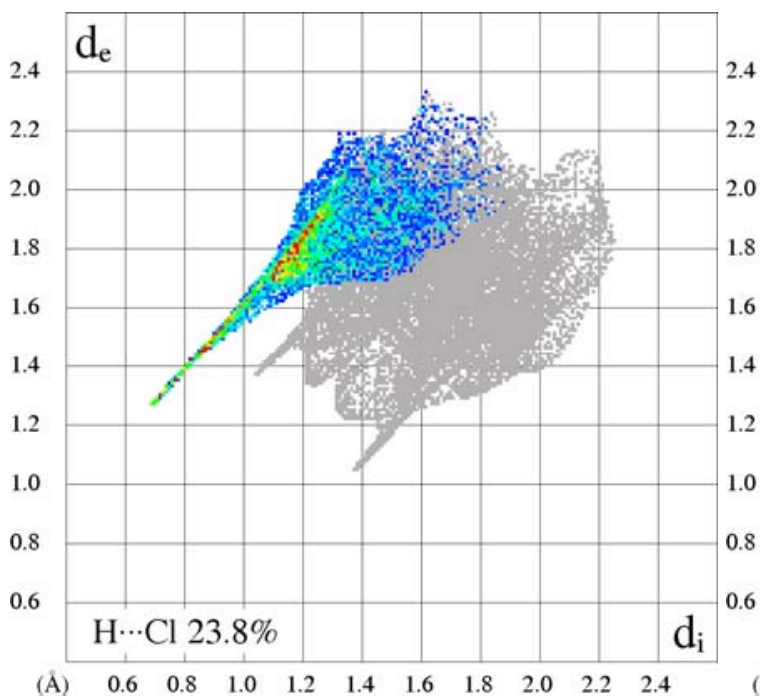

(a)

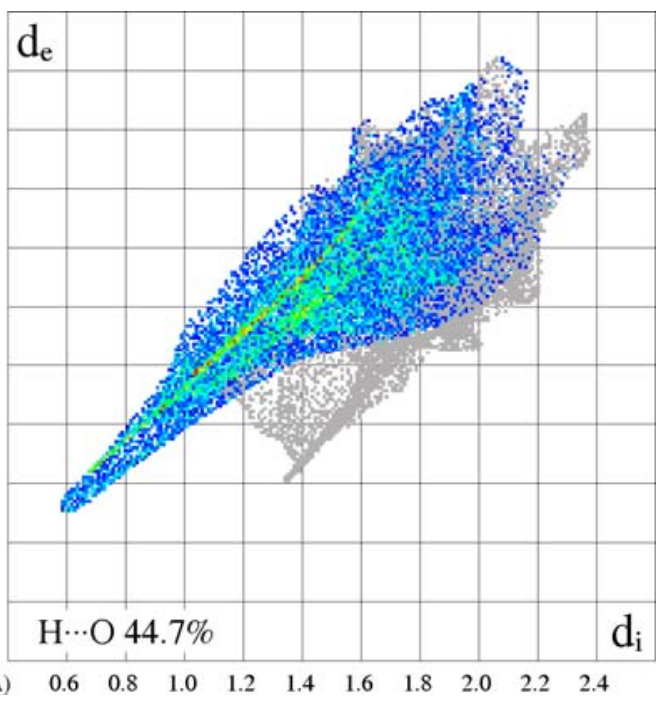

(b)

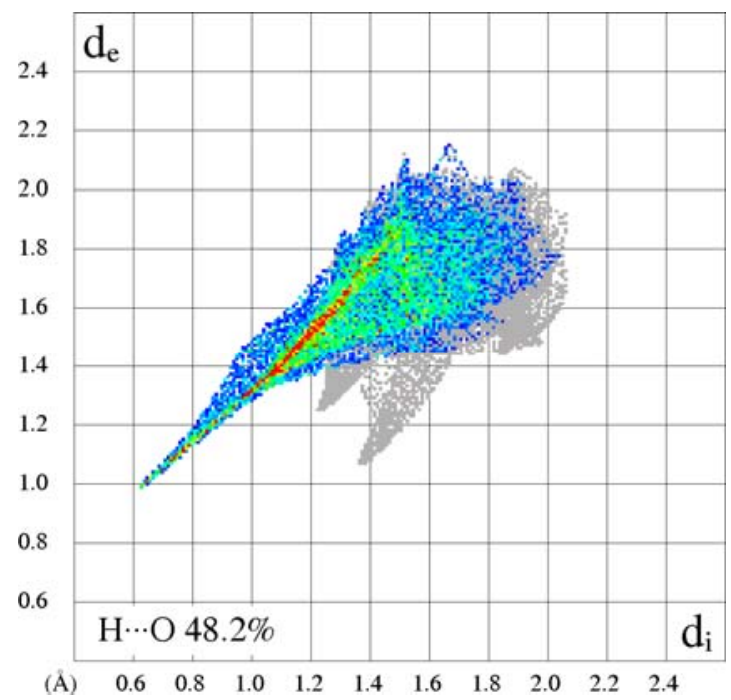

(c)

Table 3. Percent contributions of selected interactions relative to the whole Hirshfeld surface. Independent cations are termed A and B. Only major interactions are included.

\begin{tabular}{ccccccc}
\hline Interaction & \multicolumn{7}{c}{ Compound } \\
\hline & 1 & 2 & 3 & $4 \mathrm{~A}$ & $4 \mathrm{~B}$ & 5 \\
$\mathrm{O} \cdots \mathrm{H} / \mathrm{H} \cdots \mathrm{O}$ & 16.8 & 12.7 & 11.8 & 52.6 & 51.9 & 57.3 \\
$\mathrm{~N} \cdots \mathrm{H} / \mathrm{H} \cdots \mathrm{N}$ & 26.8 & 2.8 & 3.5 & 6.0 & 3.2 & 7.1 \\
$\mathrm{C} \cdots \mathrm{H} / \mathrm{H} \cdots \mathrm{C}$ & 17.1 & 12.8 & 11.6 & 8.8 & 9.1 & 6.7 \\
$\mathrm{H} \cdots \mathrm{H}$ & 35.2 & 36.1 & 36.9 & 21.3 & 22.5 & 14.1 \\
$\mathrm{H} \cdots \mathrm{Cl}$ & - & 23.8 & - & - & - & - \\
$\mathrm{H} \cdots \mathrm{Br}$ & - & - & 24.1 & - & - & - \\
\hline
\end{tabular}




\section{Experimental Section}

\subsection{1-Hydroxyimidazole (1)}

1-Hydroxyimidazole (1) [45376-79-2] was synthesized as described [7]. Single crystals were obtained from anhydrous acetone under an argon atmosphere. For m.p., H and C NMR data, see [7,10]. IR (neat): 3119, 1509, 1258, 1013, 832, 734, 651, $600 \mathrm{~cm}^{-1}$.

\subsection{1-Hydroxyimidazole Hydrochloride (2)}

The hydrochloride (2) [134561-81-2] was synthesized as described [7] and crystallized from hot anhydrous 2-propanol under an argon atmosphere, m.p. $118^{\circ} \mathrm{C}$. For $\mathrm{H}$ and C NMR data, see [8,10]. IR (neat): $3141,2502,1541,1455,1425,1358,995,763,733,679,599 \mathrm{~cm}^{-1}$.

\subsection{1-Hydroxyimidazole Hydrobromide (3)}

The hydrobromide (3) [164260-93-9] was prepared from 1-hydroxyimidazole (1, $25 \mathrm{mg}$ ) and 48\% hydrobromic acid $(42 \mu \mathrm{L})$. The mixture was dried over phosphorus pentoxide and crystallized from hot anhydrous 2-propanol under an argon atmosphere, m.p. $121{ }^{\circ} \mathrm{C}\left(119-122{ }^{\circ} \mathrm{C}\right.$ [9]). IR (neat): 3136 , 2771, 2657, 1561, 1539, 1426, 1356, 1243, 1130, 1080, 1059, 995, 897, 759, 696, 674, $595 \mathrm{~cm}^{-1}$.

\subsection{Bis(1-Hydroxyimidazolium) Sulfate (4)}

1-Hydroxyimidazole $(\mathbf{1}, 20 \mathrm{mg})$ was dissolved in $0.5 \mathrm{M}$ sulfuric acid $(0.24 \mathrm{~mL})$. The mixture was concentrated over phosphorus pentoxide and crystallized from hot anhydrous 2-propanol under argon, m.p. $86^{\circ}$ C. IR (neat): $3116,3034,2802,2708,2617,1567,1086,1050,597 \mathrm{~cm}^{-1}$.

\subsection{1-Hydroxyimidazolium Nitrate (5)}

A solution of hydrochloride $2(25 \mathrm{mg})$ in $\mathrm{H}_{2} \mathrm{O}(1 \mathrm{~mL})$ was added to a solution of $\mathrm{AgNO}_{3}(35 \mathrm{mg})$ in $\mathrm{H}_{2} \mathrm{O}(1 \mathrm{~mL})$, the precipitate removed by centrifugation, and the supernatant dried over phosphorus pentoxide. The residue was crystallized from hot 2-propanol under argon. M.p. $92-93{ }^{\circ} \mathrm{C}$. IR (neat): $3142,2845,2463,1553,1517,1417,1280,1041,1011,891,807,737,708,680,621,602 \mathrm{~cm}^{-1}$.

\subsection{Crystal Structure Determination}

Intensity data were recorded by $\omega$ scans with an Oxford Diffraction Gemini-R Ultra diffractometer using $\mathrm{Cu}-\mathrm{K} \alpha$ radiation (for $\mathbf{1}$ and 5) or Mo-K $\alpha$ radiation (for 2, 3, and 4) at $T=173(2) \mathrm{K}$. Absorption corrections were applied in all cases (multi-scan). Experimental details are summarized in Table 1. Structure solution and refinement was performed with the programs SIR2002 (direct methods) [20] and SHELXL-97 [21]. Visualization of the structures and measurements of distances and angles was performed with the program Mercury [22]. CCDC reference numbers: 899476-899480. 


\section{Conclusions}

The crystal structures of 1-hydroxyimidazole and some of its salts presented herein fill a hole which has been open for a long time. The disregard of these fundamental compounds is astounding given the existence of facile, straightforward synthetic routes for their preparation. This situation may be attributed to their hygroscopic nature which severely impedes crystallization of such polar compounds but can be overcome by appropriate techniques.

\section{References}

1. Diels, O. Über den Reaktionsverlauf zwischen Diacetyl-monoxim und Aldehyden bei Gegenwart von Ammoniak: Bildung von Dioxy-[dihydro-glyoxalinen]. Eur. J. Inorg. Chem. 1918, 51, 965-976.

2. Allan, F.J.; Allan, G.G. 1-Hydroxyimidazoles. Chem. Ind. 1964, 11, 1837.

3. Akagane, K.; Allan, F.J.; Allan, G.G.; Friberg, T.; O’Muircheartaigh, S.; Thomson, J.B. Imidazoles. II. A general synthesis for 1-hydroxyimidazoles. Bull. Chem. Soc. Jpn. 1969, 42, 3204-3207.

4. Yamada, M.; Fukui, T.; Nunami, K. Synthesis of 5-substituted methyl 1-hydroxyimidazole-4carboxylates and 5-substituted methyl 1-aminoimidazole-4-carboxylates using 3-bromo-2isocyanoacrylates (BICA). Synthesis 1995, 27, 1365-1367.

5. Bock, V.; Klötzer, W.; Singewald, N.; Strieder, G. 1-Hydroxyimidazole derivatives. I. Synthesis of 1-hydroxy- and 1-alkoxy-2,3-dihydroimidazole-2-ones. Synthesis 1987, 19, 1058-1060.

6. Hauser, H.; Klötzer, W.; Krug, V.; Rzehak, J.; Sandrieser, A.; Singewald, N. 1-Hydroxyimidazole derivatives. Part II. Synthesis and reactions of 1-benzyloxy-2,3-dihydroimidazole-2-thione. Preparation of 1-benzyloxy-1H-imidazoles. Sci. Pharm. 1988, 56, 235-241.

7. Laus, G.; Stadlwieser, J.; Klötzer, W. 1-Hydroxyimidazole derivatives. III. Synthesis of 1-alkoxy-, 1-arylalkoxy-, and 1-phenoxy-1H-imidazoles. Synthesis 1989, 21, 773-775.

8. Baus, U.; Reuther, W. Preparation of 1-hydroxyimidazoles. Eur. Pat. EP 420092 A1, 1991.

9. Begtrup, M.; Vedsø, P. Preparation of $N$-hydroxyazoles by oxidation of azoles. J. Chem. Soc. Perkin Trans. 1 1995, 243-247.

10. Eriksen, B.L.; Vedsø, P.; Morel, S.; Begtrup, M. Synthesis of 2-substituted 1-hydroxyimidazoles through directed lithiation. J. Org. Chem. 1998, 63, 12-16.

11. Laus, G.; Stadlwieser, J.; Klötzer, W. 1-Hydroxyimidazole derivatives. IV. Quaternary salts derived from 1-hydroxy-1H-imidazoles. Synthesis 1990, 22, 795-798.

12. Havez, S.; Begtrup, M.; Vedsø, P.; Andersen, K.; Ruhland, T. Directed ortho-lithiation on solid phase. J. Org. Chem. 1998, 63, 7418-7420.

13. Havez, S.; Begtrup, M.; Vedsø, P.; Andersen, K.; Ruhland, T. Palladium(0)-Catalyzed arylation of resin-bound imidazol-2-ylzinc chlorides. Synthesis 2001, 33, 909-913.

14. Eriksen, B.L.; Vedsø, P.; Begtrup, M. Synthesis of 4- and 5-substituted 1-hydroxyimidazoles through directed lithiation and metal-halogen exchange. J. Org. Chem. 2001, 66, 8344-8348.

15. Laus, G.; Schwärzler, A.; Bentivoglio, G.; Hummel, M.; Kahlenberg, V.; Wurst, K.; Kristeva, E.; Schütz, J.; Kopacka, H.; Kreutz, C.; et al. Synthesis and crystal structures of 1-alkoxy-3- 
alkylimidazolium salts including ionic liquids, 1-alkylimidazole 3-oxides and 1-alkylimidazole perhydrates. Z. Naturforsch. 2008, 63, 447-464.

16. Pinto, L.F.V.; Justino, G.C.; Vieira, A.J.S.C.; Prabhakar, S.; Lobo, A.M. Thermal rearrangement of an $\mathrm{N}$-hydroxyimidazole thiocarbamoyl derivative as a simple entry into the 4-thioimidazole motif. Arkivoc 2010, 5, 17-23.

17. Blanco, F.; Alkorta, I.; Zborowski, K.; Elguero, J. Substitution effects in $N$-pyrazole and $N$-imidazole derivatives along the periodic table. Struct. Chem. 2007, 18, 965-975.

18. Tatara, W.; Wojcik, M.J.; Lindgren, J.; Probst, M. Theoretical study of structures, energies, and vibrational spectra of the imidazole-imidazolium system. J. Phys. Chem. A 2003, 107, 7827-7831.

19. Spackman, M.A.; Jayatilaka, D. Hirshfeld surface analysis. Cryst. Eng. Comm. 2009, 11, 19-32.

20. Burla, M.C.; Carrozzini, B.; Cascarano, G.L.; Giacovazzo, C.; Polidori, G. More power for direct methods: SIR2002. Z. Kristallogr. 2002, 217, 629-635.

21. Sheldrick, G.M. A short history of SHELX. Acta Crystallogr. 2008, A64, 112-122.

22. Macrae, C.F.; Edgington, P.R.; McCabe, P.; Pidcock, E.; Shields, G.P.; Taylor, R.; Towler, M.; Van de Streek, J. Mercury: Visualization and analysis of crystal structures. J. Appl. Cryst. 2006, $39,453-457$.

(C) 2012 by the authors; licensee MDPI, Basel, Switzerland. This article is an open access article distributed under the terms and conditions of the Creative Commons Attribution license (http://creativecommons.org/licenses/by/3.0/). 